\title{
THE SUBSIDIARITY PRINCIPLE AND MARKET FAILURE IN SYSTEMS COMPETITION
}

Hans-Werner Sinn

Working Paper 5411

\author{
NATIONAL BUREAU OF ECONOMIC RESEARCH \\ 1050 Massachusetts Avenue \\ Cambridge, MA 02138 \\ January 1996
}

The author gratefully acknowledges research assistance and useful comments by Ronnie Schöb and Claudio Thum. Comments of the participants of the conference, in particular Jeremy Edwards and Richard Musgrave, are gratefully acknowledged. This paper is part of NBER's research program in Public Economics. Any opinions expressed are those of the author and not those of the National Bureau of Economic Research.

() 1996 by Hans-Werner Sinn. All rights reserved. Short sections of text, not to exceed two paragraphs, may be quoted without explicit permission provided that full credit, including $(\mathcal{C}$ notice, is given to the source. 


\title{
THE SUBSIDIARITY PRINCIPLE AND MARKET FAILURE IN \\ SYSTEMS COMPETITION
}

\begin{abstract}
Contrary to a frequent contention, systems competition cannot work when governments respect the Subsidiarity Principle. The principle implies that governments step in where markets fail. Reintroducing markets through the back door of systems competition will again result in market failure. Three models are presented which illustrate this wisdom. The first is concerned with congestion-prone public goods and shows that fiscal competition may be ruinous for the governments. The second considers the insurance function of redistributive taxation and shows that systems competition may suffer from adverse selection. The third studies the role of quality regulation and shows that systems competition may be a competition of laxity resulting in inefficiently low quality standards.
\end{abstract}

Hans-Werner Sinn

Center for Economic Studies

University of Munich

Schackstr. 4

80539 Munich

GERMANY

and NBER 


\section{Introduction}

Europe has dismantled its internal borders to grant the "four liberties" to its citizens and firms: Capital, services, labour and goods are now allowed to move freely across the borders. The new liberties will help to improve the allocation of resources and exploit the gains from trade, but they may also have noteworthy effects on the European nation states, because a period of intense systems competition has begun. Countries will compete for mobile factors of production and tax bases, perceiving strong pressures to reform their fiscal and regulatory intervention systems.

Whether this competition can be expected to be for the better or for the worse depends very much on the view of the state. Public choice theorists will welcome the possibility of taming Leviathan. ${ }^{1}$ Public finance theorists, on the other hand, may fear that the competition will erode the basic functions of the state.

For the sake of argument, this paper adopts a Panglossian view of the state which is very much in the public finance tradition, at least in the German one as represented, for example, by Wagner (1876) and Timm (1961). The state is seen as a rational institution correcting market failure and acting in the interest of its citizens. Of course, this is a disputable way to approach the problem, but it is one that may serve as a useful benchmark in further discussions of the subject. The basic assumption is that governments carry out a selection of activities which cannot be provided efficiently through private competition and that they abstain from those areas in which private competition works. The name Subsidiarity Principle has been used to characterize this assumption.

It has often been argued that the Subsidiarity Principle implies that the new Europe should grow out of a competition between the existing nation states, that no central government is needed and that it is not even desirable to harmonize its fiscal and regulatory systems. This paper comes to the opposite conclusion. It will be shown that systems competition will fail if the Subsidiarity Principle is valid. Since governments stepped in where the market failed, a reintroduction of the market through the backdoor of systems competition cannot work. It is likely to bring about the same kind of market failure that justified the

\footnotetext{
${ }^{\prime}$ However, even with a Leviathan view of the state, favourable implications of tax competition are far from being self-evident. See Edwards and Keen (1994).
} 
government intervention in the first place. This confirms the fears expressed by authors like R. Musgrave (1969), Oates (1972) or P. Musgrave (1991).

The paper will discuss three examples relevant to the Subsidiarity Principle. The first concerns public goods. Public goods cannot easily be produced privately since increasing returns in the provision of these goods implies ruinous competition. The problem of ruinous competition will be shown to reappear when states rather than firms compete with each other. The analysis will include both pure and impure public goods to allow for a motive to introduce taxes on mobile factors of production.

The next example refers to the insurance market. A person's income is a random walk through the course of his life. At birth, or even before birth, a veil of ignorance still covers the person's innate abilities and the abilities to be acquired through education. Governments can therefore provide parents with insurance against their children's risk of liftetime careers by implementing a system of redistributive taxation. By way of contrast, private insurance agencies cannot cover these risks because they can only make contracts with adults. For adults, the veil of ignorance has been lifted so that adverse selection renders a private solution impossible. It will be argued that the same kind of adverse selection problem that excluded private solutions in the first place will reappear on the level of public insurance if free migration between the states is feasible; i.e., if the states are subject to systems competition.

The third and final example discussed in this paper refers to the lemon problem. When buyers know less about the quality of the products consumed than the producers do, market equilibrium will bring about lower qualities than people would like. To overcome the inefficiency rational governments may intervene by detailing minimum quality standards in their consumer protection legislations. In the new Europe, the Cassis-de-Dijon principle, according to which a product that is legally produced in one country can be freely exported to any other country, will reintroduce the lemon problem through the back door. If consumers are unable to distinguish 15 different national quality standards per product, there will be a tendency for the single states to undercut their rivals' standards to give their own industries a competitive advantage. The result is that Europe settles to an equilibrium where the quality standards chosen are inefficiently low. 


\section{Public Goods, Congestion Charges and Systems Competition}

The discussion begins by studying the role of fiscal competition for the provision of public goods. It is an old fear that fiscal competition will erode a country's tax bases and make it difficult for the governments to collect the taxes needed to finance the provision of public goods (Oates 1972, Wilson 1986, Zodrow and Mieszkowski 1986). On the other hand, some economists argue that fiscal competition induces governments to impose benefit taxes on the mobile factors of production in exchange for the public infrastructure provided. The benefit taxes, it is maintained, will generate the revenue needed to allow an efficient supply of infrastructure (Gerber and Hewitt 1987, Wellisch 1995). It seems fair to say that the matter has not yet been fully clarified. Let us see which answers the Subsidiarity Principle will provide.

To find an answer it is important to properly model the case of public goods in the narrower sense of the word. Usually, public goods are characterized either by no rivalry or by less than perfect rivalry in consumption. This criterion is often neglected in the literature on tax competition. It will be shown that the degree of rivalry is crucial for the question of whether or not fiscal competition can be expected to work.

The model used includes the cases of pure and impure public goods. In general, the quality of a public good has two dimensions: the capacity of the facility provided, $W$, and the number of uses, $K$. To fix ideas think of a highway. The width of the highway is $W$ and the number of cars passing along it in a given period of time is $K .^{2}$ There is a unit capacity cost $\rho$ and an individual (or average) congestion cost $c$, but there is no production cost directly related to the number of uses. The congestion cost is an increasing function of $K$ and a decreasing function of $W: c=c(K, W), c_{K} \geq 0, c_{W}<0$. In the case $c_{K}=0$ the good is a pure public good in the Musgrave-Samuelson sense without any rivalry in consumption, in the case $c_{K}>0$ it is an impure public good with more or less pronounced rivalry, depending on the level of $c_{K}$.

\footnotetext{
${ }^{2}$ See Mohring and Harwitz (1962) for an explicit model of highway congestion and Oakland (1972) for an application of this model to the theory of public goods. Boadway (1980) extends the model to the theory of club goods.
} 
Suppose that the public good is an intermediate good which complements a mobile factor of production, say capital, which, together with another factor, say labour, is used for the production of some final good. Assume that the number of uses of the intermediate public good, $K$, is equal to the amount of capital invested and denote the amount of labour $L$. The production function for the final good, $f(K, L)$, is linearly homogenous and well behaved.

The country considered is small and behaves competitively in the international capital market where it faces a given net-of-tax rate of interest $r$. Due to a lack of international cooperation, only source taxes on capital and, possibly, a wage tax are available. Assume for a moment that labour is not internationally mobile and is inelastically supplied. Domestic residents own some given endowment of capital, $\bar{K}$, which they may or may not supply to the domestic market.

When the government charges a source tax at rate $\tau$, capital is invested up to the point where its marginal product equals the sum of the marginal interest, congestion and tax cost:

$$
f_{K}(K, L)=r+c(K, W)+\tau
$$

Knowing this, the government choses $\tau$ and $W$ so as to maximize the rent, $R$, that accrues to domestic residents. $R$ equals the sum of labour income, capital income, and the revenue of the source tax on capital minus the cost of providing the public facility:

$$
R=\left(f-f_{K} \cdot K\right)+r \bar{K}+\tau K-\rho W
$$

It is assumed with this formulation that any difference between $\rho W$ and $\tau K$ that may occur is absorbed by a tax imposed on, or a subsidy given to, the domestic residents. If (1) is used, this expression can be transformed to

$$
R=f(K, L)-r(K-\bar{K})-c(K, W) K-\rho W
$$


Thus the rent accruing to domestic residents equals the country's domestic product net of the interest cost of the imported capital, the congestion cost and the cost of providing the public infrastructure.

Since (1) implies that $K$ is a monotonically declining function of $\tau$, an equivalent version of the government's optimization problem is the maximization of (3) with regard to $K$ and $W$. The first-order conditions are

$$
f_{K}=r+c+c_{K} \cdot K
$$

and

$$
-c_{W} \cdot K=\rho .
$$

Equation (4) equates the marginal product of capital with its social cost, where the social cost of capital is the sum of the interest cost and the congestion cost. The congestion cost equals the individual congestion cost as perceived by each user of the public facility, $c$, plus the crowding externality which one additional user imposes on all other users, $c_{K} \cdot K$. Equation (5) is the Samuelson condition for the provision of public goods. Increasing the capacity of the facility by one unit reduces the individual congestion cost by $c_{W}$ and will thus increase capital's "willingness to pay" for the public good by the same amount. Summing up the marginal willingness to pay for a capacity increase over all units of capital and equating this sum to the marginal cost of capacity gives equation (5).

Comparing (1) and (4) shows that the government chooses a source tax rate that equals the marginal crowding externality:

$$
\tau=c_{K} \cdot K .
$$

This is the case of efficient benefit taxation which the advocates of fiscal competition seem to have in mind.

The choice of the optimal tax rate is illustrated in Figure 1. It is assumed that there is a symmetrical equilibrium in tax competition where the country considered owns the same 
amount of capital as it invests; i.e., where $K=\bar{K}$. The figure shows the individual (or average) congestion cost function $c(K, W)$ and the social marginal congestion cost function $c+c_{K} K$. The white area between the latter and the horizontal line of height $r$ is the total congestion cost and the shaded triangle above it is the tax revenue. ${ }^{3}$ The other two shaded areas characterize the factor incomes. Given the capital income and given the capacity of the public facility, $W$, the government wants to choose $\tau$ or $K$ so as to maximize the sum of labour income and tax revenue. Obviously, this is the case when $\tau$ equals the marginal crowding externality $c_{K} \cdot K$.

Figure 1. The optimal benefit tax

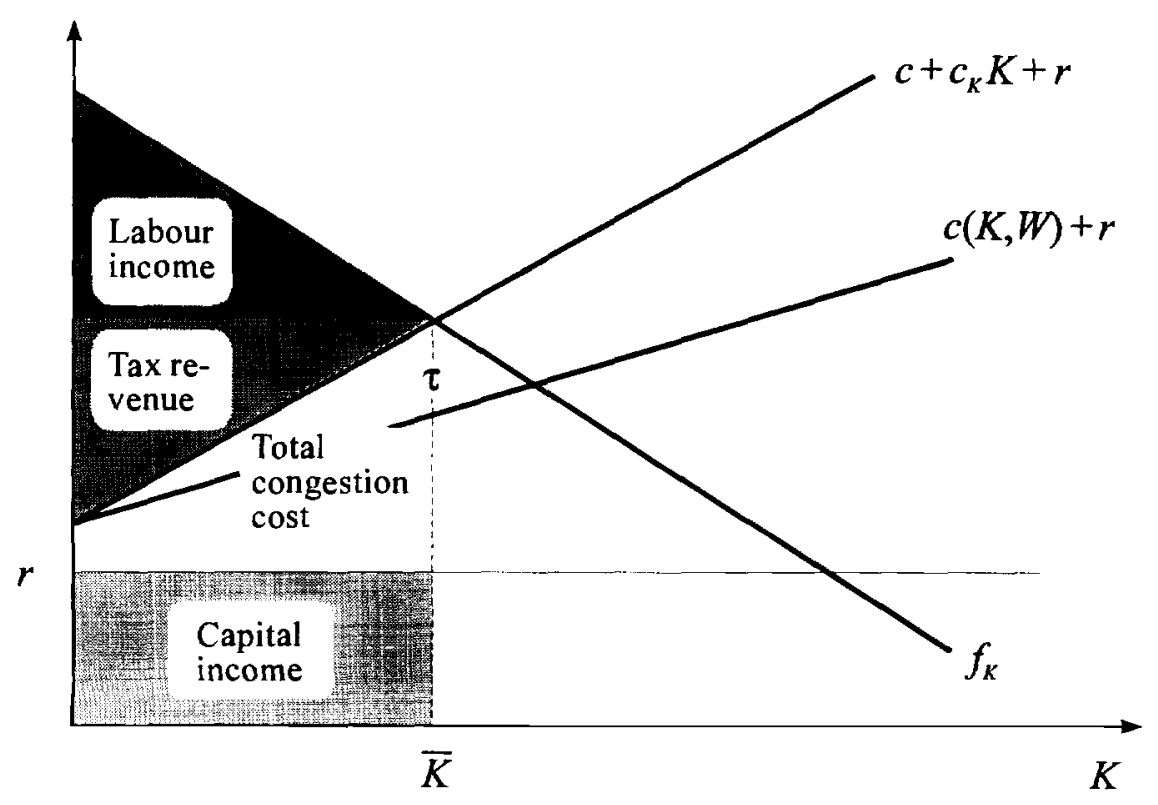

The crucial question is whether the revenue generated by the optimal benefit tax is large enough to cover the cost of providing the public facility. In the case of pure public goods $c_{K}=0$, and it follows from (6) that $\tau=0$. The optimal benefit tax is zero and the government does not collect any revenue from capital taxation. There is a fiscal deficit equal to the cost of providing the public good which has to be covered from other sources.

${ }^{3}$ To see this note that $\tau K=(\tau+c) K-K c=(\tau+c) K-\int_{0}^{K}\left[c(u, W)+c_{u}(u, W) u\right] \mathrm{d} u$. 
However, public goods are rarely pure public goods in the Musgrave-Samuelson sense. Typically there is a congestion problem, and perhaps the optimal congestion charge will generate enough revenue. It follows from Euler's theorem that

$$
c_{K} \cdot K+c_{W} \cdot W=\lambda c
$$

where $\lambda$ is the degree of homogeneity of the congestion cost function. Inserting the first order conditions (5) and (6) into (7) gives

$$
\tau K=\rho W+\lambda c K
$$

Equation (8) shows that the government will be able to recover the cost of providing the intermediate public good if, and only if, $\lambda \geq 0$; i.e., if the congestion cost function has a degree of homogeneity of no less than zero. Doubling both the number of customers and the expenditure for the public good must not result in lower individual congestion costs or, equivalently, doubling the number of customers must require a doubling, or more than a doubling, of the public expenditure for the congestion cost to stay constant. This is a variant of the usual exclusion of increasing returns to scale in a competitive market equilibrium. ${ }^{4}$

If the Subsidiarity Principle is valid there is little hope that cost recovery is possible, because all those public goods for which $\lambda \geq 0$ holds would be privately supplied, and the government would specialize exclusively on public goods with $\lambda<0$.

It is easy to show that a competitive private market solution is possible if, and only if $\lambda \geq 0$. Suppose there are $i=1, \ldots ., n$ identical private clubs that offer the public facility at the respective user charges $\tau_{1}, \ldots, \tau_{n}$. In a competitive equilibrium the users are indifferent between the clubs supplying the facilities. ${ }^{5}$ The sum, $P$, of the user charge $\tau_{i}$ and the congestion cost $c\left(K_{i}, W_{i}\right)$ must therefore be the same for all clubs:

\footnotetext{
${ }^{4}$ Bewley (1981) criticized Tiebout (1961) for neglecting the role of increasing returns to scale. The present model can be seen as an extension of Bewley's criticism to the case of congested public goods.

${ }^{5} \mathrm{Cf}$. Buchanan's (1965) seminal work on club goods and the overview of the literature given by Sandler and Tschirhart (1980).
} 


$$
P \equiv \tau_{i}+c\left(K_{i}, W_{i}\right)=\tau_{j}+c\left(K_{j}, W_{j}\right) \forall i, j=1, \ldots, n
$$

The single club takes $P$ as given and choses $K_{i}$ and $W_{i}$ so as to maximize its profit:

$$
\max _{K_{i}, W_{i}}\left[P-c\left(K_{i}, W_{i}\right)\right] K_{i}-\rho W_{i}
$$

Necessary conditions for an interior optimum are

$$
-c_{W} K_{i}=\rho
$$

and

$$
\tau_{i}=c_{K} K_{i}
$$

They fully parallel conditions (5) and (6). The private club, too, charges a fee that incorporates the crowding externality and it provides a capacity that satisfies the Samuelson condition for the optimal provision of public goods. Since an application of Euler's theorem again implies an equation like (8), it follows that competitive private markets require $\lambda \geq 0$ as contended. If $\lambda<0$, there were ruinous competition. Given the number of uses, $K$, the best a club could do is choose a capacity according to (10). And given the capacity, $W$, the best it could do is charge a fee according to (11). However, neither policy permits the club to avoid bankruptcy. This completes the proof that the Subsidiarity Principle implies $\lambda<0$ for the government sector and that a fiscal deficit is unavoidable.

Governments cannot go bankrupt as easily as private firms can. The fiscal deficit can, in principle, be financed by taxing the fixed factor - labour in the present case. Indeed attracting capital at "dumping" prices would be optimal from the worker's point of view even if they had to sacrifice some of their wage income provided only that the fiscal deficit is less than this income. Nevertheless the distributional consequences will be far from trivial, and a substantial resistence from the disadvantaged workers must be feared.

Particularly severe consequences are to be expected when labour, too, finds ways to escape the tax burden. It is true that currently European workers are far from being perfectly 
mobile, but things may change in the long run. To see in which direction increased mobility might ultimately lead, consider the limiting case of perfect mobility and suppose each country carries out a policy that maximizes the rent accruing to its initial population assuming that this population is entitled to receive the government budget surplus if any. Let the initial population be $\bar{L}$, while $L$ is the total work force consisting of the initial population and immigrants, $L-\bar{L}$. Workers will face a given net-of-tax wage rate $l$ in the community. When the national labour tax rate is $\sigma$, their employment will satisfy the condition

$$
f_{L}(K, L)=l+\sigma
$$

Instead of (3) the government is now maximizing

$$
R=f(K, L)-r(K-\bar{K})-l(L-\bar{L})-c(K, W) K-\rho W
$$

by chosing $K, L$ and $W$. Again (4) and (5) are necessary conditions for an optimum as before. However, an additional necessary condition is

$$
f_{L}(K, L)=l
$$

which, because of (12) implies that $\sigma=0$. Since equations (6) - (8) remain valid and $\lambda<0$ holds due to the Subsidiarity Principle, it follows that there is a fiscal deficit that cannot be covered. Obviously, a competitive equilibrium fails to exist, and it does so for the same reason that makes a private competitive equilibrium infeasible when $\lambda<0$; i.e., when there are increasing returns in production.

It is difficult to theorize about what will happen instead of the emergence of a competitive equilibrium. However the analogy with private markets suggests that there will be a ruinous competition of states, leading ultimately to a concentration of economic activities in one or only a few countries which will then no longer be forced to act competitively. 
There are a number of remarks that are appropriate to qualify this theoretical result. They include the role of other fixed factors, the mobility assumption, the introduction of further public goods that benefit the workers or the assumption of competitive behaviour. However, instead of pursuing them here, let us rather turn to the next example for the Subsidiarity Principle.

\section{Redistribution, Insurance and Fiscal Competition}

The second important fiscal activity of the state in addition to the production of public goods is the redistribution of incomes. Redistribution can have many reasons including charity, social and political stabilization, or ethics and justice.

Arguably the most important reason is the insurance it provides in an uncertain world. Redistribution and insurance are two sides of the same coin, their difference lies primarily in the time of judgement. Ex post, every insurance contract involves redistribution. Ex ante, before the dice of destiny are cast, much of the foreseen or announced redistribution can be seen as insurance against the risk of income variations. Many authors including Friedman (1953), Harsanyi (1953) and Rawls (1971) have pointed this out.

Given that there are private insurance markets that offer protection against risk, the crucial question is which borderline the Subsidiarity Principle draws between government and private insurance. Why are risk markets imperfect and to what extent can governments do better than the market?

The literature has distinguished two basic reasons for market failure in insurance. The first is moral hazard. There can be moral hazard due to a reduction in care (ex ante moral hazard) and due to an excessive demand for indemnification resources (ex post moral hazard). Writers like Spence and Zeckhauser (1971) and Pauly (1968) have analyzed the problems involved. Apart from Arnott and Stiglitz's (1989) suggestion of taxing the consumption of dangerous commodities like tobacco or alcohol, moral hazard in the insurance context hardly justifies government intervention. The government would have to know more about the behaviour of the insurees than the insurance companies to overcome the asymmetric information causing the moral hazard problem. 
This is different with the second reason for market failure, adverse selection (see Pauly 1974, Rothschild and Stiglitz 1976, Wilson 1979 or Eisen 1979). When insurance companies cannot distinguish between good and bad risks, but the potential insurees can, the good risks will not find a pooling insurance contract attractive because they know that they would have to subsidize the bad risks with their premium. ${ }^{6}$ The typical result is a breakdown of the insurance market for the good risks and, with a continuum of different types of risks in the market, even a market for bad risks may never come to an existence (Riley 1979).

Unlike moral hazard, the government can correct the market failure due to adverse selection because it does not need any superior information. In many cases it can provide welfare improvements simply by making the insurance or redistribution obligatory.

The main reason for this possibility is that the government can introduce the insurance earlier, at a stage when no one knows who will be the good or the bad risks. Government redistribution is an insurance against being a bad risk and as such it may be welcomed by all citizens before destiny has lifted its veil of ignorance.

To be more specific, consider the preferences of parents or parents to be. At or before the time of birth the parents do not know whether their child will be handicapped or healthy, gifted or untalented. They are therefore interested in obtaining insurance against the lifetime income variation resulting from these differences. The market cannot provide this insurance since this would imply that the parents sign a bondage contract for their children from which these children could not escape even if they wished to do so. Whether the absence of bondage is a market failure or the result of a government intervention that requires another intervention to patch the consequences can be left open here. The course of history has long made its decision about the matter and given this decision, there is little doubt that private markets cannot provide the type of career insurance which is the essence of income redistribution through the government budget.

Private insurance markets simply come too late. The "children" have to be adults to obtain insurance, but then their differences are already visible. If both the insurer and the potential insurees can monitor the differences, they will never agree to a contract that

\footnotetext{
${ }^{6}$ When the insurance companies enjoy market power, separating equilibria with variable premia are possible.
} This paper is only concerned with competitive solutions. 
eliminates them, and if only the insurees can, insurance markets may not come into existence because of the adverse selection described.?

The impossibility of signing bondage contracts on behalf of one's children explains the borderline between private and government insurance. The redistributive tax system provides insurance against a bad endowment with innate abilities and bad luck during growth towards adulthood including the severe lifetime consequences this may have. The private insurance markets cover some of the minor risks that remain.

Consider a simple insurance model that illustrates some of the problems involved. Suppose for a moment that the economy considered is closed and assume again that output is produced with capital, $K$, and labour, $L$, where $L$ is measured in terms of efficiency units of labour rather than real persons. As before, $f(K, L)$ is the linear-homogenous production function. The wage of an efficiency unit of labour equals its marginal product,

$$
l=f_{L}(K, L)
$$

and the rate of interest equals the marginal product of capital,

$$
r=f_{K}(K, L)
$$

Let the number of efficiency units supplied by one worker be $\theta_{1} \cdot \theta_{2}$ where $\theta_{1}$ and $\theta_{2}$ are arbitrarily random variables with a mean of one: $E \theta_{1}=E \theta_{2}=1 . \theta_{1}$ is the risk arising from innate abilities that become known only at the beginning of adulthood and $\theta_{2}$ reflects later reasons for wage variations such as promotion, employment or health risks. Assume that the $\theta$ 's are stochastically independent across time and individuals, but are identically distributed for all individuals in the economy. If the economy is large, these assumptions imply that $f_{L}$, and hence $l$, is non-stochastic.

\footnotetext{
${ }^{7}$ For a related discussion of this theme see Sinn (1995b).
} 
Assume that a worker faces an additional stochastically independent risk in terms of a random loss $C, C \geq 0$, which is deducted from his wage income. Moreover, let every worker own a capital endowment $\bar{K}$. Without taxation and market insurance, his total income will be

$$
Y=\theta_{1} \cdot \theta_{2} \cdot l-C+r \bar{K} .
$$

Obviously the risk involved in $C$ is insurable since it is the same for all workers. Respecting the Subsidiarity Principle the government will therefore not include this risk in its redistribution policy. In a competitive private market fair insurance will be available at a premium $P=\alpha E C$ where $\alpha$ is the degree of coverage. A globally risk averse individual will chose a full coverage contract $(\alpha=1)$, and equation (17) becomes

$$
Y=\theta_{1} \cdot \theta_{2} \cdot l-E C+r \bar{K} .
$$

Things are different with $\theta_{1}$ and $\theta_{2}$. As explained above, the riskiness of innate abilities, $\theta_{1}$, cannot be privately insured since the contract can only be made after $\theta_{1}$ has become known to at least one of the parties. The contract would involve a known resource transfer from one part of the society to another to which the net contributors of funds would never agree.

$\theta_{2}$ may also not be insurable. $\theta_{2}$ is a multiplicative factor for $\theta_{1}$ which augments the differences in innate abilities adding more randomness at a later period of time. Insurance is possible if the realization of $\theta_{1}$ is visible to both parties because the premium can then be conditioned on the value of $\theta_{1}$. However, if only the workers know their type while the insurance companies cannot distinguish between them, there is the typical adverse selection problem.

Because of the stochastic independence of $\theta_{1}$ across the workers, the realized distribution of $\theta_{1}$ is identical with the probability distribution of $\theta_{1}$ as seen from an ex ante perspective. If $\theta_{1}$ has a small, and $\theta_{2}$ a large, variance adverse selection is not very strong and a private insurance solution, albeit with less than full coverage for the better risks, is possible. 
However, if the variance of $\theta_{1}$ is large relative to that of $\theta_{2}$, the market will break down at least for the better risks and perhaps even for all risks. The appendix presents an example where $\theta_{1}$ and $\theta_{2}$ are such that none of the workers will be able to find wage insurance in the private market.

In line with the Subsidiarity Principle, the non-insurability of $\theta_{1}$ and $\theta_{2}$ is the justification for government insurance through the redistributive tax system. Assume there is a linear labour income tax at rate $\tau$ and a lump sum rebate in the form of a monetary transfer or a public good which equals the expected tax revenue:

$$
T=\tau \cdot l
$$

The probability distribution of after-tax income will then be given by

$$
Y=\theta_{1} \cdot \theta_{2} \cdot l(1-\tau)+T-E C+r \bar{K}
$$

The first two moments of this distribution are

$$
\mu=l-E C+r \bar{K}
$$

and

$$
\sigma=(1-\tau) \cdot S\left(\theta_{1} \cdot \theta_{2}\right) \cdot l
$$

where $S(\cdot)$ is the standard deviation operator. ${ }^{8}$ The expected income $\mu$ is not changed due to the government intervention and the standard deviation $\sigma$ shrinks to $(1-\tau)$ times its pre-tax value. Since the distributions which are attainable with alternative values of $\tau$ all belong to the same linear class it is clear that expected utility will increase for a globally risk averse worker when a redistributive tax system is introduced. ${ }^{9}$

\footnotetext{
${ }^{8}$ Note that the assumptions made about $\theta_{1}$ and $\theta_{2}$ imply that $E\left(l \cdot \theta_{1} \cdot \theta_{2}\right)=l \cdot E \theta_{1} \cdot E \theta_{2}=l$.

${ }^{9}$ In the model as set up the optimal tax rate would be $100 \%$. A more sophisticated model would have to include a counterweight to the direct welfare gain from insurance by allowing for a moral hazard effect, but it would also have to include the beneficial risk taking effects that can be expected from redistributive taxation (see Sinn 1995a). With moral hazard the optimal tax rate is typically less than $100 \%$, but it is also more than $0 \%$. As the
} 
To bring about a welfare increase it is not necessary for the government to have superior information than the private insurance market. However two important assumptions have to be met. First, the redistribution scheme must be known before $\theta_{1}$ becomes known. Second, the government must be able to force the "good risks" to participate by paying their taxes.

The second condition is crucial for understanding the implications of fiscal competition among redistributive tax systems. Suppose the borders are opened and both capital and labour can freely migrate across them. This liberty will not affect the private insurance contract, but it will affect the insurance through redistributive taxation since the government loses its power to enforce the payment of taxes. People can migrate between countries after $\theta_{1}$ and/or $\theta_{2}$ have become known, but they cannot "migrate" between insurance contracts after $C$ has become known. Let $i=1, \ldots, n$ denote the set of competing countries and suppose there is a migratory equilibrium. All countries will have the same rate of interest

$$
r_{i}=r_{j} \quad \forall i, j=1, \ldots, n,
$$

and the wage income net of redistribution will also have to be the same in all countries:

$$
\theta_{1} \cdot \theta_{2} \cdot l_{i} \cdot\left(1-\tau_{i}\right)+T_{i}=\theta_{1} \cdot \theta_{2} \cdot l_{i} \cdot\left(1-\tau_{j}\right)+T_{j} \quad \forall i, j=1, \ldots, n
$$

Note that it is not sufficient that the expected utility is the same in each country. Since migration is not limited to the ex-ante phase, the realized utility ex post must also be the same everywhere, and this is only the case if the realized net-of-tax labour income is the same for each value of $\theta_{1} \cdot \theta_{2}$. This becomes clear if (19) is used to write (24) in the form

$$
l_{i}\left[\theta_{1} \cdot \theta_{2}-\tau_{i}\left(\theta_{1} \cdot \theta_{2}-1\right)\right]=l_{j}\left[\theta_{1} \cdot \theta_{2}-\tau_{j}\left(\theta_{1} \cdot \theta_{2}-1\right)\right] \forall i, j=1, \ldots, n
$$


Obviously, this equation can hold uniformly for all variates of $\theta_{1} \cdot \theta_{2}$ if, and only if, $l_{i}=l_{j}$ and $\tau_{i}=\tau_{j} \forall i, j=1, \ldots, n$.

While a symmetrical solution with redistributive taxation is the only possible candidate for an equilibrium, it is easy to show that an equilibrium does not, in fact, exist if governments act on behalf of their citizens. Note that (16), (23) and the linear homogeneity of the production function imply that a migration of workers will always be coupled with a migration of capital so as to keep the factor prices fixed at the international level.

Consider an initial situation where condition (25) holds. The single country will have an incentive to deviate from this condition by reducing its tax rate $\tau$ a little and reducing the transfer $T$ because this will attract net contributors of public funds and deter the net receivers. Suppose $\tau$ and $T$ are varied so as to satisfy the budget constraint (19) for a given size and composition of the population. Then there is clearly a Pareto improvement with regard to all those people the national government could possibly care about. "Rich" domestic residents with $\theta_{1} \cdot \theta_{2}>1$ will be better off since they pay less, and so it will be with the rich who immigrate from other countries. The "poor" with $\theta_{1} \cdot \theta_{2}<1$ would lose from the tax cut if they stayed, but they will not stay. By migrating to other countries they can maintain their income position: The government which finds itself only with net contributors of public funds could even afford to subsidize the emigration of the poor. This makes it obvious that a redistributive equilibrium in systems competition will not exist. The welfare state has no survival chance when an unbridled tax competition is allowed.

The breakdown of the welfare state is a clear efficiency loss. Despite the fact that there is a Pareto improvement from a single country's point of view, given the behaviour of all other countries, there is a Paretian welfare loss if all countries behave in the way described. The increase in expected utility which redistributive taxation generates from an ex ante point of view is no longer available. The only stable equilibrium with fiscal competition is one where $\tau_{i}=\tau_{j}=0 \forall i, j=1, \ldots, n .^{10} \mathrm{~A}$ single country that deviates from this equilibrium by raising $\tau$ to positive values would deter the rich and attract the poor thus creating a fiscal deficit. And a

\footnotetext{
${ }^{10}$ This result can also be derived for a redistribution among factors that are not perfect substitutes as in the present model. See Wildasin $(1991,1992)$. The difficulty of redistributing income between mobile factors has been observed by a number of authors including R. Musgrave (1969) and Oates (1972).
} 
single country that deviates by lowering $\tau$ below zero would deter the poor and attract the rich, which again implies a fiscal deficit since it would now be the rich who are net receivers and the poor who are net contributors of public funds.

The deeper economic reason for the efficiency loss resulting from systems competition is again the Subsidiarity Principle, the fact that the government insures those risks which cannot be insured privately. A private solution is infeasible because private redistribution contracts cannot be made early enough, and without a contract, redistribution cannot be enforced. Adverse selection becomes unavoidable. In a closed economy, the government can remedy the situation because it can provide insurance through the tax law. It has the power to enforce the necessary resource transfer between the lucky and the unlucky without having to rely on voluntary private contracts. In an open economy, however, this power vanishes with the right to migrate across the borders. The good risks leave the insurance state just as they leave the insurance company. Obviously, systems competition suffers from the same type of adverse selection that justified the government intervention in the first place. Only if the government did not respect the Subsidiarity Principle and offered signed insurance contracts under the rules of the civil law as private companies do, would a competition of insurance states then be able to work.

\section{Cassis-de-Dijon, the Lemons Problem and the Competition of Laxity}

Consider now the final example for the role of the Subsidiarity Principle: the competition of quality standards. The establishment of the origin principle for product standards is often seen as one of the great achievements of the Common European market. A commodity that has been legally produced in one country which respects all the existing product regulations there can be freely exported to any other country in the community. The importing country cannot, in general, require its own product specifications to be met. The breakthrough came with the Cassis-de-Dijon judgement of the European Court in Straßburg in 1979 which has since been applied to a number of other cases, including beer imports into Germany and pasta imports into Italy. 
The great advantage of the Cassis-de-Dijon judgement is that it helps prevent the single states engaging in protectionist practices. However, there may be not only advantages. The drawback is a potential erosion of consumer protection standards which may result from the national governments attempting to give their industries a competitive lead by relaxing their regulatory constraints. Competition of laxity is an appropriate description of this phenomenon.

Whether or not the competition of laxity can be seen as welfare reducing depends again very much on the role of the state. If governments violate the Subsidiarity Principle there may be cases in which a relaxation of regulatory constraints improves the efficiency of the system. However, if the Subsidiarity Principle is respected, as assumed in this paper, then consumer protection laws correct market failure, and if they correct market failure, it may not be wise to subject these laws themselves to a market's decision. The market for consumer protection laws may again suffer from market failure.

The kind of market failure justifying consumer protection laws is Akerlof's (1970) lemons problem. If consumers cannot distinguish product qualities, the sellers cannot convincingly differentiate the price of a product according to quality. The sellers, who are better informed than the consumers, will therefore withold the good qualities and oversupply the bad qualities. Consumers will know what the average quality supplied in the market is and will therefore not pay too much, but, as long as they cannot determine the quality of the goods they buy beforehand, the market will be trapped in a low quality equilibrium.

The lemons problem is often presented as an adverse selection problem, where the sellers have a given set of consumer durables which they can either use themselves (existing cars!) or sell in the market. However, there are equally severe moral hazard problems in production involved. If the consumers cannot distinguish qualities, the producers will save production cost by reducing their product quality, and, in equilibrium, the qualities produced will be lower than those that would have been offered to informed owners. The national consumer protection laws and guide lines set out regulatory measures to avoid this welfare loss. In many cases the measures include the obligation to inform the consumers, but often they simply define minimum quality standards. 
With most of the millions of products traded in a market economy such standards may not be necessary since consumers are sufficiently well informed about qualities. This is the case with products whose quality can be detected by using them and which are frequently purchased. Expensive products also do not suffer much from the lemon problem since it pays for the consumers to acquire the relevant information before making a purchase. However, the lemon problem may be severe with other products. These are products which are not frequently purchased, whose quality can only be detected with a small probability with use or whose value is too low to justify intensive information gathering. Food is a good example. Here, minimum quality standards are often defined in terms of maximum content of dangerous ingredients. These can be very harmful but are difficult to detect by experience since there is only a small probability that the damage (cancer!) will occur. Also, food is relatively cheap. Typically, the variety of food products bought by a single person is so large, and the value per item so small, that it would not be worth becoming a specialist in food chemistry before going to the supermarket. Hiring a food specialist through the government may be the more efficient solution.

The rationale for consumer protection and the risks involved with systems competition can easily be demonstrated by a simple model. Let $x$ be the quality of a lemon good and $y$ the quality of another good that can be transformed into $x$, say leisure. The unit cost of producing $x$ by giving up $y$ is $c(q), c^{\prime}>0, c^{\prime \prime}>0$, where $q$ is the quality chosen. Let $y$ be the numeraire and $P$ the price of $x$. Assume the consumer can observe the average quality, $\tilde{q}$, in the market, but not the quality of the single item he buys. The consumer's problem is to maximize his (well behaved) utility function,

$$
\max _{x, y} U(x)+V(q)+y
$$

subject to the budget constraint

$$
\bar{y}=y+P x .
$$


The consumer cannot choose $q$ but assumes that $q$ equals $\tilde{q}$. The first order condition for his problem is simply Gossen's second law:

$$
U^{\prime}(x)=P
$$

The producer's problem is

$$
\max _{q, x}[P-c(q)] x
$$

The first-order conditions are

$$
P=c(q)
$$

and

$$
c^{\prime}(q)=0 \text { for } x>0
$$

Equations (32) and (34) imply that

$$
U^{\prime}(x)=c(q)
$$

Equation (35) and (36) they define the market equilibrium under moral hazard. Equation (35) shows that the firm makes no effort to increase quality and equation (36) ensures that the consumer's marginal willingness to pay for a unit of the commodity equals marginal cost. The solution is illustrated in Figure 2. The flatter of the two downward sloping curves is the geometrical locus of points where (36) is satisfied. The vertical line is the geometrical locus of points where (35) is satisfied. It is assumed that this is the case for some positive value of $q$, call it $q^{*}$. The intersection of the two lines defines the lemons equilibrium. 
Figure 2: The competition of laxity

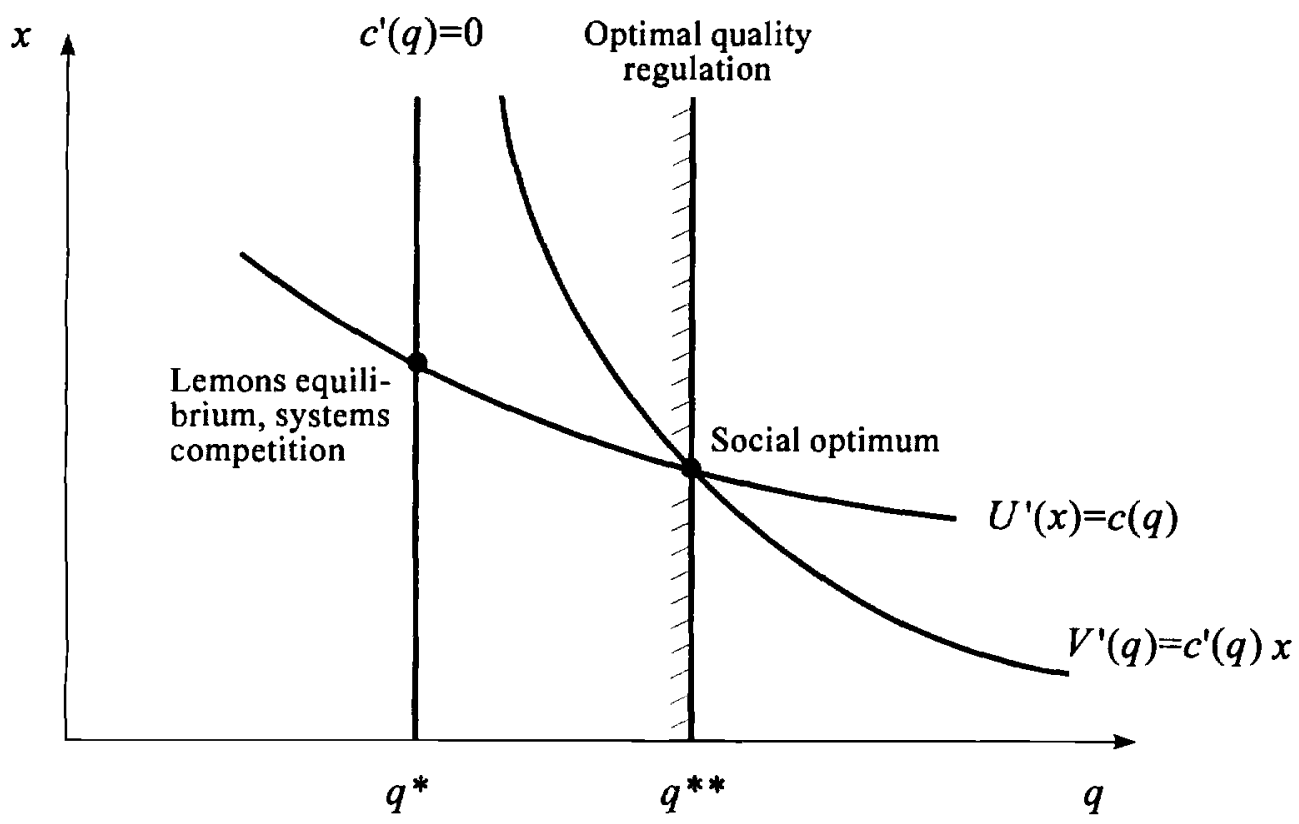

To see that the equilibrium is inefficient, consider the social planner's problem

$$
\max _{x, q} U(x)+V(q)+\bar{y}-c(q) x
$$

The necessary conditions for this problem are (36) and

$$
V^{\prime}(q)=c^{\prime}(q) x
$$

Equation (38) shows that it is efficient to balance the marginal utility from a quality increase with its marginal costs. Since $V^{\prime}>0$ while $c^{\prime \prime}>0$, a higher quality than the one chosen by the market turns out to be optimal. In Figure 2, the social optimum is characterized by the intersection between the flat curve representing condition (36) and the steeper curve representing (38). Assume that the point of intersection exists; i.e., that there is a social optimum. Then the solution point must be to the right of $q^{*}$. This becomes obvious if it is noted that $V^{\prime}$ and $x$ are non-negative and that the curve representing (38) can only asymptotically reach the vertical line above $q^{*}$ as $q$ shrinks to $q^{*}$ : When $q$ approaches $q^{*}$, $c^{\prime}(q)$ approaches zero and so $x$ has to go to infinity to keep the right-hand side of (38) in 
balance with $V^{\prime}(q)$. Thus the quality provided by the market is insufficient. There is indeed a lemons equilibrium.

An optimal kind of government intervention to correct the market failure is the introduction of a minimum quality standard $q^{* *}$, as illustrated in the figure. Since quality is costly the firm will choose $q=q^{* *}$ and the equilibrium will continue to satisfy equation (36). Obviously the policy of setting minimum standards can, in principle, correct the market failure and increase the welfare of the community. Of course, the government needs superior information to enforce the standard properly, but, unlike the insurance case where moral hazard occurs with private households, it is not implausible to assume that the government can set up institutions that monitor the producers.

What if free trade according to the Cassis-de-Dijon principle is introduced? An optimistic view would be that the consumers could now freely choose among the national regulations knowing what quality standards they imply. The price of $x$ would be conditioned on the respective national standard of consumer protection as defined by $q^{* *}$. In equation (31) $P$ would be replaced with $P\left(q^{* *}\right)$ and the consumer would assume that $q=q^{* *}$.

The national standard would become a choice variable and, in the household's optimum, the marginal utility from choosing a better standard would have to be equal to the marginal expenditure increase this would involve:

$$
V^{\prime}\left(q^{* *}\right)=P^{\prime}\left(q^{* *}\right) x
$$

The national government, on the other hand, would choose $q^{* *}$ so as to maximize the profits earned by its firms. In (33) $P$ would have to be replaced with $P\left(q^{* *}\right)$ and $q$ with $q^{* *}$. The government's profit maximizing choice would be characterized by equality of the marginal revenue from lifting the national standard and the marginal production cost incurred by doing so:

$$
P^{\prime}\left(q^{* *}\right) x=c^{\prime}\left(q^{* *}\right) x
$$


Note that the government would not in addition have to consider its national consumers' preferences. Since the competitive country is a price taker in the international market for consumer goods, its consumers would not be affected by the change in the national standard. As always in competitive markets, production and competition decisions would be perfectly separated.

Taken together, equations (31) and (40) imply the efficiency condition (38). Thus it seems that a competition of national quality standards could work and bring about the optimal quality level.

Again, however, the assumptions underlying such an optimistic result violate the Subsidiarity Principle. There are certainly many commodities about which consumers could be expected to be sufficiently knowledgeable to choose between different national quality standards. However, when the Subsidiarity Principle is valid these are exactly those commodities where the government does not intervene. Consumer protection is instead exclusively limited to those goods where consumers can be expected to have an informational deficit: the goods with low values, the rarely purchased goods, and the goods whose harmful properties will only be detected with a small probability. These are precisely the goods for which a choice between a multitude of national quality standards would be utterly confusing for the consumers. The same difficulties which justified government intervention in the closed economies of the old Europe reappear when governments rather than firms compete with one another in the open economies of the new Europe.

Obviously, with confused consumers, $P$ cannot be conditioned on the national standard $q^{* *}$ and hence the profit maximizing government will choose $q^{* *}$ so as to minimze production cost; i.e., it will set

$$
c^{\prime}\left(q^{* *}\right)=0
$$

just as the firms would do if left to themselves [see (35)]. Again there is an underprovision of quality as illustrated in Figure 2. When the government respects the Subsidiarity Principle, systems competition is a competiton of laxity which gets stuck in a lemons equilibrium. 


\section{Conclusions}

For the sake of argument this paper pursued the implications of two strong, but straightforward assumptions. The one assumption was that the state respects the Subsidiarity Principle, that it is an institution which acts on behalf of its people and helps them overcome the collective irrationalities associated with their individual choices. The other assumption was that governments act competitively. The paper has shown that the two assumptions do not fit together. In general, an efficient equilibrium in systems competition does not exist when the Subsidiarity Principle holds.

It follows that economists should be cautious when trying to model systems competition. It is not legitimate to make assumptions about the information and production possibilities of governments which are usually considered as plausible in the modelling of private market economies. There is a selection bias, at least in the weak sense that, of the government's numerous activities, a larger proportion is unsuitable for a competitive environment than of the economic activities carried out by private agents.

The analysis also has consequences for the design of the new Europe. A corner solution, where no central government is formed and all policy decisions are left to the nation states and voluntary contracts between them, is not suggested by the model. It may be useful to further discuss the question of whether at least some sort of centralization may be necessary to take the implications of the Subsidiarity Principle into account.

Europe still is a long way from such a situation. It is entering a difficult phase where some of the dangers described in this paper may soon become virulent before countervailing measures are in place. History will show how this experiment ended. 


\section{Appendix: The non-existence of a market for wage insurance}

This appendix shows that under the assumptions of the model of section 3 the insurance market for wage insurance may break down completely, leaving no market for bad risks. Assuming that individuals can simultaneously buy contracts from different competitive firms, the analysis can be confined to the possibility of pooling equilibria.

Assume that the utility function exhibits constant relative risk aversion between zero and one and is identical for all individuals. Let $E C=r \bar{K}$ so that the individual's income is $l \cdot \theta_{1} \cdot \theta_{2}$. The insurance market opens after $\theta_{1}$ and before $\theta_{2}$ has been revealed. Let $\theta_{1}$ be uniformly distributed in the range $0 \leq \theta_{1} \leq \theta_{1}^{\max }$ and assume that $\theta_{2} \geq 0$.

If an equilibrium in the insurance market exists, there is a critical value $\bar{\theta}_{1}$ with $0<\bar{\theta}_{1} \leq \theta_{1}^{\max }$ such that the "good" risks with $\theta_{1}>\bar{\theta}_{1}$ buy no insurance and the "bad" ones with $\theta_{1} \leq \bar{\theta}_{1}$ buy at least some insurance. Using these properties it will be proved by contradiction that an equilibrium may not exist at all.

Let $\alpha$ be the degree of insurance coverage and assume for a moment that all risks choose the same degree of coverage. Note that the average "quality" of abilities as measured by $\theta_{1}$ is $\bar{\theta}_{1} / 2$. When fair insurance is available, the income distribution of individuals of type $\bar{\theta}_{1}$ will be characterized by a mean of

$$
\begin{aligned}
\mu & =\alpha l \bar{\theta}_{1} / 2+(1-\alpha) l \bar{\theta}_{1} \\
& =l \bar{\theta}_{1}\left(1-\frac{\alpha}{2}\right)
\end{aligned}
$$

and a standard deviation of

$$
\sigma=(1-\alpha) l \bar{\theta}_{1} S\left(\theta_{2}\right)
$$

where $S($.$) is the standard deviation operator. Since the distribution class to which all$ distributions attainable by varying $\alpha$ is a linear one and relative risk aversion is constant, an expected utility maximizer has a homothetic indifference curve system as shown in Figure 3. 
Figure 3: The non-existence of a market for wage insurance

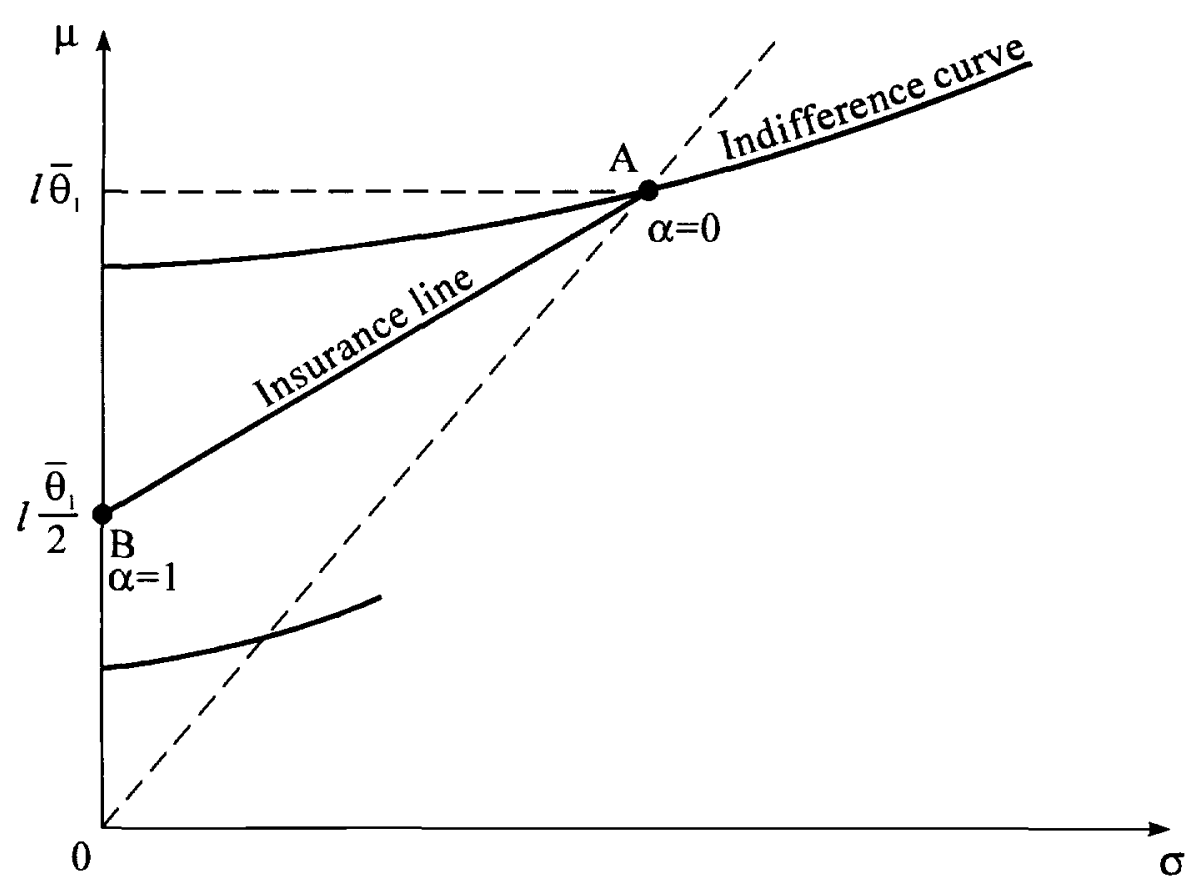

Let point $\mathrm{A}$ characterize the distribution attainable by the best of the bad risks (i.e., those with $\theta_{1}=\bar{\theta}_{1}$ ) when $\alpha=0$ and $B$ the one attainable when $\alpha=1$. The distributions located on the straight line between $A$ and $B$ - the insurance line - are attainable for risks of type $\bar{\theta}_{1}$ by varying $\alpha$ in the range between zero and one.

Suppose now individuals of type $\bar{\theta}_{1}$ are allowed to vary $\alpha$ arbitrarily while all others choose a given non-negative value of $\alpha$. Since individuals of type $\bar{\theta}_{1}$ have a density mass of zero, this will not affect the conditions under which they can buy insurance. If they decide to buy some insurance, the slope of the indifference curve passing through $\mathrm{A}$ must be higher than that of the insurance line. However, in the case considered in the figure, risk aversion is so low that the opposite is true. Risks of type $\bar{\theta}_{1}$ will stay uninsured if all risks with $\theta_{1}<\bar{\theta}_{1}$ choose a given (identical) non-negative degree of insurance coverage. They will a fortiori stay uninsured if the assumption that $\alpha$ is the same among the other risks (i.e., those with $\theta_{1}<\bar{\theta}_{1}$ ) is relaxed. Whatever the exact participation pattern of the other risks: because of the assumption of identical preferences it will always be true that the preferred degree of coverage is a declining function of the quality of innate abilities as measured by $\theta_{1}$. Thus the conditions under which individuals of type $\bar{\theta}_{1}$ can find insurance will be even worse than assumed in the 
figure. This proves that they will not participate, a contradiction to the assumption that they will.

Note that no particular value of $\bar{\theta}_{1}$ has been assumed for this proof other than the assumption that $0<\bar{\theta}_{1} \leq \theta_{1}^{\max }$. It is easy to see that the non-existence of an equilibrium for a particular value of $\bar{\theta}_{1}$ implies the non-existence for all other feasible values of $\bar{\theta}_{1}$ in this range. In Figure 3, a variation of $\bar{\theta}_{1}$ will move point $A$ along a ray through the origin and point $B$ along the ordinate in a way that keeps the slope of the insurance line unaffected. Due to the assumption of constant relative risk aversion the indifference curve slope remains constant along a ray through the origin. Thus, when the indifference curve slope is lower than the slope of the insurance line at one particular position of $A$, this will be true for all feasible positions of $\mathrm{A}$ along a ray through the origin. This completes the proof that under the assumptions of the paper adverse selection may be strong enough to prevent an insurance market for wage risks from coming into existence. Even a market for the worst of the bad risks would then not be available. 


\section{References}

Akerlof, G.A. (1970): "The Markets for Lemons: Quality, Uncertainty and the Market Mechanism", Quarterly Journal of Economics 84, 488-500.

Arnott, R., and J. E. Stiglitz (1989): "The Welfare Economics of Moral Hazard", in: H. Loubergé, ed., Risk, Information and Insurance: Essays in Memoriam of Karl Borch. Norwell, MA: Kluwer Academic Publishers, 91-122.

Bewley, T. F. (1981): "A Critique of Tiebout's Theory of Local Public Expenditures", Econometrica 49, 713-740.

Boadway, R. (1980): "A Note on the Market Provision of Club Goods", Journal of Public Economics 13, 131-137.

Buchanan, J. M. "An Economic Theory of Clubs", Economica 23, 1965, 1-14.

Edwards, J., and M. Keen (1995): "Tax Competition and Leviathan", forthcoming in European Economic Review.

Eisen, R. (1979): Theorie des Versicherungsgleichgewichts, Duncker und Humblot: Berlin.

Friedman, M. (1953): "Choice, Chance and the Personal Distribution of Income", Journal of Political Economy 61, 277-290.

Gerber, R. F., and Hewitt, D. P. (1987): "Decentralized Tax Competition for Business Capital and National Economic Efficiency", Journal of Regional Science 27, 451-460.

Harsanyi, J. C. (1953): "Cardinal Utility in Welfare Economics and the Theory of Risk Taking", Journal of Political Economy 61, 434-435.

Oakland, W. H. (1972): "Congestion, Public Goods and Welfare", Journal of Public Economics 1, 339-357.

Oates, W. E. (1972): Fiscal Federalism, Harcourt, Brace, Jovanovich: New York, Chicago et al.

Mohring, H., and M. Harwitz (1962): Highway Benefits. An Analytical Framework, Northwestern University Press: Chicago. 
Musgrave, P. (1991): "Fiscal Coordination and Competition in an International Setting", in: L. Eden, ed., Retrospectives on Public Finance, Duke University Press: Durham and London.

Musgrave, R. (1969): "Theories of Fiscal Federalism", Public Finance 24, 521-536.

Pauly, M. (1974): "Overinsurance and Public Provision of Insurance. The Roles of Moral Hazard and Adverse Selection", Quarterly Journal of Economics 88, 309-327.

Rawls, J. (1971): A Theory of Justice, Harvard University Press: Cambridge, Mass.

Riley, J. G. (1979): "Informational Equilibrium", Econometrica 47, 331-359.

Rothschild, M., and J. Stiglitz (1976): "Equilibrium in Competitive Insurance Markets. An Essay on the Economics of Imperfect Information", Quarterly Journal of Economics 90, 626-650.

Sandler, T., and J. T. Tschirhart (1980): "The Economic Theory of Clubs: An Evaluative Survey", Journal of Economic Literature 18, 1481-1521.

Sinn, H.-W. (1994): "How Much Europe? Subsidiarity, Centralization and Fiscal Competition", Scottish Journal of Political Economy 41, 85-107.

---, (1995a): "A Theory of the Welfare State", forthcoming in the Scandinavian Journal of Economics.

---, (1995b): "Social Insurance, Incentives and Risk Taking", Paper prepared for the 51st IIPF Congress, Lisbon 1995.

Spence, M., and R. Zeckhauser (1971): "Insurance, Information, and the Individual Action", American Economic Review 61, 380-391.

Tiebout, Ch. M. (1961): "An Economic Theory of Fiscal Decentralization", in: Public Finances: Needs, Sources and Utilization, A conference of the Universities-National Bureau Committee for Economic Research, Princeton University Press: Princeton, 7996.

Timm, H. (1961): "Das Gesetz der wachsenden Staatsausgaben", Finanzarchiv 21, 201-247. 
Wagner, A. (1876): Allgemeine oder theoretische Volkswirtschaftslehre: Erster Theil. Grundlegung, Winter'sche Verlagsbuchhandlung: Leipzig und Heidelberg.

Wellisch, D. (1995): Dezentrale Finanzpolitik bei hoher Mobilität, J. C. B. Mohr (Paul Siebeck): Tübingen.

Wildasin, D.E. (1991): "Income Redistribution in a Common Labor Market", American Economic Review 81, 757-774.

---, (1992): "Relaxation of Barriers to Factor Mobility and Income Redistribution", in: P. Pestieau, Public Finance in a World of Transition, Proceedings of the 47th Congress of the International Institute of Public Finance, St. Petersberg 1991, Supplement to Public Finance 47, 216-230.

Wilson, Ch. (1979): "Equilibrium and Adverse Selection", American Economic Review 69, papers and proceedings, 313-317.

Wilson, J. (1984): "A Theory of Interregional Tax Competition", Journal of Urban Economics 19, 296-315.

Zodrow, G., and P. Mieszkowski: "Pigou, Tiebout, Property Taxation, and the Underprovision of Local Public Goods", Journal of Urban Economics 19, 356-370. 